\title{
LA JUSTICIA O LA INJUSTICIA DEL CONTRATO DE TRABAJO DESDE EL PENSAMIENTO MORAL DE ARTHUR SCHOPENHAUER ${ }^{*}$
}

\author{
THE JUSTICE OR INJUSTICE OF THE WORK CONTRACT \\ FROM THE MORAL THOUGHT OF ARTHUR SCHOPENHAUER
}

Edward Duván OROzco PEREIRA**

\section{Resumen:}

Este texto es fruto de una investigación adelantada como trabajo de grado para optar por el título de magíster en filosofía. El objetivo principal de esta investigación es determinar las condiciones bajo las cuales un contrato de trabajo sería justo o injusto desde el pensamiento moral del filósofo alemán Arthur Schopenhauer, específicamente en la obra El mundo como voluntad y representación $I$.

El cuerpo del texto se divide en tres partes. En el primer capítulo, los conceptos de injusticia-justicia, propiedad y trabajo son analizados en detalle. En el segundo, el concepto de contrato y su aplicación se explican detalladamente en relación con otros conceptos como fidelidad y honradez. Además, se exponen el Estado y el derecho positivo como fundamentados en un contrato, el contrato social. En el tercer y último capítulo se desarrolla el objetivo principal de esta investigación y, por ende, se da respuesta a la pregunta planteada. Para esto, se ahonda un poco más en los conceptos de propiedad y contrato, así como en la mentira y su importancia, a la vez que se recurre a fuentes especializadas que permitirán obtener información de otras obras de Schopenhauer distintas a su obra magna, El mundo como voluntad y representación.

\section{Palabras clave:}

Trabajo, propiedad, justicia, mentira, intercambio, contrato laboral.

Artículo recibido el 11 de febrero de 2020 y aceptado para su publicación el 3 de diciembre de 2020.

** Profesor de la Universidad Industrial de Santander, correo: edwardorozco09@ hotmail.com, ORCID: https://orcid.org/0000-0001-9395-0926.

Problema. Anuario de Filosofía y Teoría del Derecho, núm. 15, enero-diciembre de 2021, pp. 443-483 Ciudad de México, ISSN 2007-4387, se distribuye bajo una Licencia Creative Commons ReconocimientoNo-Comercial-Sin Derivados 4.0 Internacional (CC BY-NC-ND 4.0). 
EDWARD DUVÁN OROZCO PEREIRA

\begin{abstract}
:
This paper is the result of research carried out to obtain a master's degree in philosophy. The main objective of this research is to determine the conditions under which a labor contract is fair or unfair based on the moral thought of the German philosopher Arthur Schopenhauer, specifically in his work The World as Will and Representation I.

The body of the text is divided into three parts. In the first chapter, the concepts of injustice-justice, property and labor are analyzed in detail. The second part elaborates on the concept of contract and its application in connection with other concepts like loyalty and honesty. In addition, the State and positive law are depicted as being based on a contract, the social contract. The third and last section addresses the main objective of this research and, therefore, responds the question at hand. To this end, we delve into the concepts of property and contract, as well as lying and its importance, while drawing on specialized sources that provide information on Schopenhauer's other works besides his magnum opus, The World as Will and Representation.
\end{abstract}

\title{
Keywords:
}

Work, Property, Justice, Lie, Exchange, Work Contract. 
SumARIO: I. Introducción. II. Propiedad, justicia-injusticia y trabajo en Arthur Schopenhauer. III. El contrato en el pensamiento de Schopenhauer. IV. Condiciones de un contrato de trabajo justo en el pensamiento moral de Arthur Schopenhauer. V. Conclusiones. VI. Referencias.

\section{INTRODUCCIÓN}

El objetivo principal de esta investigación es determinar las condiciones bajo las cuales un contrato de trabajo sería justo o injusto desde el pensamiento moral de Arthur Schopenhauer. Esto implicará al menos tres momentos que equivalen a cada uno de los capítulos de este texto.

En el primero se hará necesario que los conceptos de injusticiajusticia, propiedad y trabajo sean expuestos detalladamente con el fin de aclarar sus acepciones para el filósofo alemán y así propender por la precisión conceptual que se requiere para la respuesta a la interrogante planteada, a saber, ¿en qué condiciones un contrato de trabajo es justo o injusto desde el pensamiento moral de Arthur Schopenhauer? Esto requerirá, de igual manera, de un corto esquema del concepto de voluntad en el filósofo alemán y su importancia en la filosofía moral.

En el segundo momento serán detallados el concepto de contrato y su aplicación, tanto individualmente como en su relación con otros conceptos como fidelidad y honradez. Además, será necesario exponer el origen moral del Estado y del derecho positivo, y cómo se fundamentan ambos en un contrato, el contrato social.

El tercer momento será el definitivo de este documento. En este se desarrollará el objetivo principal de esta investigación y, por ende, se responderá a la pregunta de investigación planteada. Para esto, se hará necesario ahondar un poco más en los conceptos de propiedad y contrato. Además, la mentira y su importancia deberán estudiarse, a la vez que se recurrirá a fuentes especializadas que permitirán obtener información de otras obras de Schopenhauer distintas a su obra magna. 
Cabe aclarar que esta investigación se realiza desde el libro El mundo como voluntad y representación I (1818 ${ }^{1}$ ) de Arthur Schopenhauer. Además, se recurre a autores de literatura especializada que han estudiado gran parte de la obra del filósofo alemán y proveen elementos para responder a los interrogantes aquí planteados. Igualmente, es preciso señalar que la versión en español utilizada en esta investigación corresponde a la traducción de Pilar López de Santa María, publicada por la Editorial Trotta en el 2009. Así que los términos usados en este trabajo corresponden a la versión mencionada.

Asimismo, en esta investigación se parte de que el término trabajo tiene una polisemia que requiere ser dilucidada si se busca comprender el pensamiento schopenhaueriano. En la primera acepción el trabajo es visto como una actividad que busca un determinado fin, sin que este implique necesariamente un acuerdo entre dos individuos. En la segunda concepción se plantea el trabajo como una relación laboral en la cual dos individuos acuerdan voluntariamente el intercambio de determinados bienes a cambio de la prestación de un servicio personal.

De acuerdo con lo anterior, en la estrecha relación entre estas dos acepciones se encuentra el problema: determinar si es posible que al interior de una relación laboral no se cometa injusticia al quitarse parte del producto que por su trabajo material sería propiedad del trabajador.

La hipótesis de la que se parte es que sí puede haber un contrato de trabajo justo desde la filosofía moral de Schopenhauer y la tarea fundamental de esta investigación es determinar cuáles son las condiciones bajo las cuales un contrato de esta naturaleza es justo o injusto.

\section{PROPIEDAD, JUSTICIA-INJUSTICIA Y TRABAJO EN ARTHUR SCHOPENHAUER}

Para iniciar el estudio detallado de los conceptos de propiedad, justicia-injusticia y trabajo es importante reconocer el momento en el

1 Al respecto es importante recalcar que no hay uniformidad sobre el año en el que se publicó esta obra. Sobre este punto se sigue a Luis Moreno, texto que también se recomienda para ahondar en los detalles biográficos de este pensador alemán: Moreno, Luis, Schopenhauer. Una biografía, Madrid, Trotta, 2014. 
que estos se introducen en la obra magna de Schopenhauer. Es igual de relevante recordar que el objetivo final de su empresa filosófica es descubrir la identidad última de la cosa en sí (o noúmeno²), a saber, la Voluntad, entendida como fundamento último de toda realidad y que se analizará luego con más detenimiento.

Hasta el $\S 62$, que es el apartado en el que estos conceptos son estudiados a profundidad y que se encuentra en el cuarto libro de la obra, el filósofo alemán ha explicitado totalmente al menos tres momentos de su empresa filosófica. En el primero ${ }^{3}$ de los cuatro libros que componen El mundo como voluntad y representación, Schopenhauer realiza la primera consideración del mundo como representación y se centra en su intrínseca relación con el principio de razón. En el segundo libro, ${ }^{4}$ plantea la primera consideración del mundo como voluntad, centrado, fundamentalmente, en cómo se lleva a cabo su objetivación. La segunda consideración del mundo como representación se encuentra en el tercer libro ${ }^{5}$, en el que la idea platónica se muestra como la representación independiente del principio de razón. Para finalizar su obra, en el cuarto libro ${ }^{6}$, se encuentra la segunda consideración del mundo como voluntad, la cual se enfoca en la afirmación y la negación de la voluntad de vivir al alcanzar el autoconocimiento.

Es, precisamente, en este último libro donde los conceptos claves de esta investigación toman relevancia. En el parágrafo §62 del cuarto libro, Schopenhauer emprende la explicación de un área muy

2 Pilar López sostiene que el término más apropiado para referirse a esta acepción del término Voluntad es cosa en sí. El vocablo noúmeno —el cual rechazaimplica, según esta autora, al menos una posibilidad de aprehender la Voluntad a través del conocimiento: "En Schopenhauer la cosa en sí no tiene nada que ver con lo nouménico sencillamente porque no es susceptible de representación, sea ésta abstracta o intituitiva. Hablar de un conocimiento de cómo sea una cosa en sí, esto es, al margen del conocer mismo, implica para él una contradicción". López, Pilar, "Voluntad y sexualidad en Schopenhauer", Thémata, Sevilla, núm. 24, 2000, pp. 115136.

3 Schopenhauer, Arthur, El mundo como voluntad y representación I, trad. de Pilar López de Santa María, Madrid, Trotta, 2009, pp. 49-144.

4 Ibidem, pp. 145-220.

5 Ibidem, pp. 221-324.

6 Ibidem, pp. 325-476. 
basta del saber filosófico: ${ }^{7}$ la moral, el derecho y la relación entre estos. El primero de los conceptos centrales de esta investigación que trae a discusión el filósofo alemán es el de injusticia. Sin embargo, la introducción de este concepto exige sintetizar algunos puntos que ha demostrado previamente en su obra, específicamente, la manera en que la voluntad, en sus acepciones, ${ }^{8}$ y el cuerpo están íntimamente relacionados.

Antes de esto, hay que tener presente que en este texto se seguirá la tendencia de la dogmática schopenhaueriana de distinguir estas acepciones del término voluntad por la presencia de la inicial mayúscula o su ausencia:

Y he escrito aquí Voluntad con letra mayúscula, con lo que nos estamos refiriendo a la Voluntad única, al substrato único de la pluralidad fenoménica, a la cosa-en-sí, tomando con él la expresión prestada de su ídolo y, en cierto modo enemigo, que es Kant. Pero es sabido que, en bastantes casos, voluntad en Schopenhauer debe escribirse con minúscula, porque no se refiere a la Voluntad cosa-en-sí, sino a la voluntad de cada indi-

7 Quizá en muy pocas páginas. Se presenta aquí un ejemplo de lo que afirmaba Kant: "Bien podrá decir el abate Terrasson que si se mide el tamaño de un libro; no por el número de sus páginas, sino por el tiempo que se necesita para entenderlo, de más de un libro se podría decir que sería más breve, si no fuese tan breve", Kant, Immanuel, Crítica de la razón pura, trad. de Mario Caimi, México, Fondo de Cultura Económica-UAM-UNAM, 2009, AXIX, p. 11. Las itálicas son propias de la fuente citada. Mucho más si se tiene en cuenta el estilo de Schopenhauer y que también reconoce Sergio Rábade: "Retomando alguna idea aludida al principio, hay que reconocer que el estilo de Schopenhauer, que muchas veces sucumbe al dato curioso, a la comparación divertida y, con más frecuencia, a la brillantez de expresión, no le facilita al estudioso el intento de aristar con rigor temas, nociones o problemas. Uno se ve obligado a perseguir expresiones de pasada, textos fragmentarios, pero acaso nunca encuentra el desarrollo tematizado del problema que persigue", Rábade, Sergio, "El cuerpo en Schopenhauer", Logos. Anales del Seminario de Metafísica, Madrid, vol. 23, 1989, p. 139. Sobre la actualidad de Schopenhauer y su mote de pesimista, consúltese: Carrillo, Lucy, "Schopenhauer: sobre individuos y sociedad", Estudios de filosofía, Medellín, núm. 37, 2008.

8 Sobre el lugar que ocupa la voluntad en el desarrollo argumentativo de El Mundo como Voluntad y Representación, consúltese: Muñoz-Reja, Vicente, "Schopenhauer: estrategias de acreditación del mundo como voluntad", Bajo Palabra, Madrid, núm. 2, 2007. 
viduo humano, es decir, a una pluralidad, que forzosamente habrá que considerar como fenoménica, de voluntades. ${ }^{9}$

Por un lado, el término voluntad en Schopenhauer implica individualidad, es decir, y en contraposición a su otra acepción más universal, se da de manera diferente en cada individuo. Es por esta razón que es común en esta acepción el uso del plural: siempre que se mencionan o correlacionan a dos o más individuos, se relacionan dos o más voluntades. Bryan Magee reconoce que al interior de esta concepción individualizada del término voluntad se encuentran, a su vez, dos aspectos de este término.

El primero refiere a un aspecto volitivo y activo de la voluntad individual. Schopenhauer en este punto equipara y afirma como una única y misma cosa a las acciones del cuerpo y a los actos de voluntad. Ambos son movimientos físicos que necesariamente implican manifestaciones externas y tienen una particularidad: pueden ser conocidos fenoménicamente, es decir, mediados por los sentidos, o como fenómenos sin la mediación de estos.

El cuerpo y sus acciones son aprehendidos por los otros individuos y, de cierta manera también por el individuo mismo que posee ese cuerpo, como un fenómeno, es decir, como un objeto material externo:

El acto de voluntad y la acción del cuerpo no son dos estados diferentes, conocidos objetivamente y unidos por la ley de causalidad, no están en la relación de causa y efecto, sino que son una misma cosa que se da de dos maneras completamente distintas: una vez inmediatamente y otra en la intuición en el entendimiento. La acción del cuerpo no es otra cosa que el acto de voluntad objetivado, es decir, dado en la intuición. ${ }^{10}$

En cambio, los actos de voluntad son conocidos inmediatamente por el sujeto volente, no como un noúmeno, ya que esto sería por sí mismo una contradicción, sino como el fenómeno más directo e inmediato entre todos los fenómenos posibles, ya que no requiere

9 Rabade, Sergio, "El cuerpo en Schopenhauer", cit., p. 140.

10 Schopenhauer citado en Magee, Bryan, Schopenhauer, trad. de Amaia Bárcena, Madrid, Cátedra, 1991, p. 138. 


\section{EDWARD DUVÁN OROZCO PEREIRA}

la mediación de los sentidos para su conocimiento, incluso solo se requiere del tiempo como su condición de posibilidad. Esto es quizá uno de los aspectos más destacables de la manera como Schopenhauer pensó la relación sujeto-objeto en el autoconocimiento. Cuando un sujeto se conoce a sí mismo no es el sujeto cognoscente, a su vez, el objeto conocido, sino que este objeto es su voluntad: el hombre se conoce a sí mismo como volente, mas no como cognoscente.

El segundo aspecto es el pasional o afectivo. En este recaen todas las afecciones y pasiones que puede sentir el individuo. A diferencia del aspecto volitivo, su manifestación externa no es necesaria aunque sí tiene implicaciones en el cuerpo-. ${ }^{11}$ Esto no quiere decir que no se dé en algunos casos, como el rubor en el rostro del hombre avergonzado o la respiración agitada en el aterrorizado, sino que esta manifestación no siempre ocurre y, en últimas, la forma más constante de conocer este tipo de afecciones es de manera inmediata y directa sin la mediación de los sentidos y solo por aquel individuo que las siente:

Tan poderoso y tan extenso es el conocimiento directo del que disponemos acerca de lo que está sucediendo dentro de estos objetos físicos que son nuestros cuerpos - un fluido polifónico, semejante a una orquesta en la multiplicidad de sus complejidades y de su significación- que no se le puede hacer justicia con una breve descripción verbal. Y sabemos directa e ineludiblemente que estamos experimentando estas cosas: ningún conocimiento podría ser más inmediato o más seguro. ${ }^{12}$

Schopenhauer engloba en este aspecto a aquellas manifestaciones de la voluntad como los anhelos, las aspiraciones, los deseos, la esperanza, el amor, la alegría, el odio, el temor, la cólera, la tristeza, entre otros. Su relevancia no es de subestimar, ya que tienen implicaciones en la actividad, es decir en el aspecto volitivo, espe-

11 “Todo sentimiento o emoción que experimentamos, por leve que sea, tiene una consecuencia física de alguna clase, que manifiesta en una leve tensión o distensión muscular, la presión sanguinea, la temperatura o el nivel de actividad de algún órgano o glándula; las conmociones de la voluntad y los movimientos del cuerpo siempre son correlativos". Ibidem, p. 149.

12 Ibidem, pp. 142 y 143. 
cíficamente en que estas afecciones moldean la manera en la que se manifestará la voluntad en sus actos, en las resoluciones y en las acciones del cuerpo.

Como se mencionó anteriormente, el individuo conoce fenoménicamente esta voluntad individuada a través de las acciones del cuerpo y los actos de la voluntad. La división de la realidad en fenómeno y noúmeno implica también que al hombre, al ser un sujeto conocedor que se encuentra inmerso en esta realidad con su cuerpo como un objeto material, también se le aplique esta división:

Si todos los objetos materiales son en un sentido fenómeno y en otro sentido noúmeno, entonces también los seres humanos, como los objetos materiales, han de tener esta naturaleza dual, y por lo tanto en algún sentido hemos de ser noúmeno. ${ }^{13}$

Bajo la premisa adicional de que, al percibir la totalidad de los fenómenos, el noúmeno de esta totalidad de fenómenos percibida debe ser la misma en todos los individuos, se concluye que el conocimiento de la realidad total, incluyendo el noúmeno, está en el autoconocimiento, específicamente, en el autoconocimiento de la voluntad, entendida como ese fenómeno que se le da inmediatamente al hombre.

Sin embargo, esto no implica que haya un conocimiento del noúmeno, que sería por sí mismo una contradicción irresoluble. Cuando el hombre se interna en el conocimiento de su voluntad se da cuenta de que la mayoría de la constitución de la voluntad de cada individuo es inaccesible a su conocimiento: ${ }^{14}$ no puede tener certeza de cómo funciona realmente en su aspecto volitivo, ni de qué es en realidad lo que está sintiendo y por qué (aspecto afectivo):

13 Ibidem, p. 154.

14 Tesis que muchos estudiosos de la obra de Schopenhauer consideran como precursora del psicoanálisis: "Estos párrafos son notables en muchos sentidos, al menos porque constituyen una exposición inconfundiblemente clara y explícita de una idea que hoy en día se suele atribuir a Freud, que aún no había nacido. El punto que dejan claro de mayor importancia para el argumento que nos ocupa es que, aunque la voluntad puede ser consciente, no lo es necesariamente, y de hecho por lo general no lo es. La comprensión de esto posibilita una profundización de nuestra comprensión de la relación cuerpo-voluntad". Ibidem, p. 148. 
Schopenhauer argumentó minuciosamente, y con un rigor psicológico que carece de precedentes, que la evidencia empírica apunta hacia la conclusión de que no sólo la mayor parte de nuestros pensamientos y sentimientos nos son desconocidos, sino que la razón de ello es un proceso de represión que es en sí mismo inconsciente. ${ }^{15}$

Además de esto, la voluntad de la que el hombre es consciente no puede ser por sí misma noúmeno, ya que ella es ya un fenómeno, una representación del individuo. Por ende, esta voluntad de la que es consciente el hombre debe ser a su vez fenómeno de otra cosa. Y es precisamente en este momento en donde toma relevancia la segunda acepción del término Voluntad.

La parte más íntima del ser del hombre, aquella de la que parte y es manifestación su voluntad no puede ser conocida directamente. De igual manera que el noúmeno, cualesquiera que sean sus características, no está al alcance del conocimiento del hombre. Así, el noúmeno posee la naturaleza de esa voluntad que, como se mencionó anteriormente, es inconsciente e innacesible a la conciencia.

$Y$ esto que es inconsciente e innacesible a la conciencia es también aquello que se encuentra tras los movimientos de todo lo material. La imposibilidad de conocer a detalle la voluntad de cada hombre es una muestra de cómo la Voluntad se expresa a su vez en las demás cosas:

Todo lo que se presenta ante nuestros órganos de los sentidos y nuestro intelecto como materia en movimiento es, en su naturaleza íntima, incognoscible, esta fuerza inconsciente, ambos son la misma cosa que se manifiesta de diferentes maneras, así como nuestro movimiento físico y nuestra voluntad son una misma cosa manifestada de formas diferentes. Todo el universo es la objetivación de esta fuerza. ${ }^{16}$

Así, Schopenhauer decide denominar esta fuerza o energía usando términos que le atribuye Magee-Voluntad en su segunda acepción. Y usa este vocablo porque es el nombre de ese fenómeno que el hombre conoce más directa e inmediatamente:

15 Ibidem, p. 147.

16 Ibidem, p. 155. 
En todos los procesos de emergencia de un acto de voluntad desde las oscuras profundidades de nuestro ser íntimo a la conciencia, tiene lugar una transición de la cosa en sí, atemporal, al fenómeno. En consecuencia, el acto de voluntad no es más que el fenómeno más claro y más evidente de la cosa en sí; sin embargo, se sigue de ello que, si todos los demás fenómenos pudieran ser conocidos por nosotros de la misma forma íntima e inmediata, tendríamos que considerarlos iguales a la voluntad en nosotros. En este sentido, digo que la naturaleza íntima de todo es voluntad, y llamo a la voluntad la cosa en sí. ${ }^{17}$

Así, Voluntad significa la cosa en sí, que transciende todo plano de representación y es, a su vez, la naturaleza íntima de todo lo que es. Con esto, se transciende el alcance particular de la primera acepción y, además, se transciende toda posibilidad de conocimiento de lo que esta realmente es, ya que para mantenerse como noúmeno tiene que ser completamente incognoscible e incomprensible para el hombre.

Para finalizar este corto esquema sobre el término Voluntad, es importante traer a colación la definición que sintetiza Magee y que permite dejar a un lado varios errores de interpretación que pueden surgir del uso habitual de este término en la actualidad, especialmente, aquellos que lo relacionan con el plano teleológico o vitalista:

A partir de ahora llamaremos al noúmeno "voluntad", y por ella entenderemos una fuerza universal, carente de objetivo, no individualizada, no viva, tal y como se manifiesta, por ejemplo, en el fenómeno de la gravedad. ${ }^{18}$

Además, es importante recordar que para Schopenhauer el cuerpo es una manifestación fenoménica, es decir, temporal y espacial, de la voluntad de vivir, entendida esta como el fenómeno más ordinario, directo y correcto en el hombre (y otros animales), como se mencionó anteriormente. Y que la afirmación de la voluntad de vivir es, a su vez, la afirmación del cuerpo que necesariamente se manifiesta fenoménicamente. ${ }^{19}$ La afirmación del cuerpo se muestra a través

17 Schopenhauer citado en ibidem, p. 157.

18 Ibidem, p. 161.

19 Se destaca la importancia que tiene este concepto en el pensamiento de Scho- 


\section{EDWARD DUVÁN OROZCO PEREIRA}

del uso de las fuerzas de las que este dispone para su preservación, por tanto, la afirmación de la voluntad de vivir que se da a través de la afirmación del cuerpo se muestra a través del uso de estas fuerzas. De esta manera, la afirmación de la voluntad de vivir de cada individuo se da en la aplicación de las fuerzas que su cuerpo posee para propender por su preservación e integridad.

La causa de esto yace en el principium individuationis, ${ }^{20}$ a partir del cual la voluntad de vivir se manifiesta de manera particular en muchos individuos objetivados en un cuerpo determinado. Este principio, a su vez, es el origen del egoísmo que se da entre los individuos y que cimienta el alejamiento que, en principio, existe entre ellos y que, además, es el reto que tienen que afrontar estos para vivir en comunidad. Al respecto, Cabos diferencia el principio de in-

penhauer: "Schopenhauer tiene, entre muchas otras cosas, el mérito fundamental (al menos para alguien no espiritualista, como es mi caso) de defender la constitutiva corporeidad de todo viviente sin caer en un reductivismo corporeísta", Pérez Jara, Javier, "La importancia del cuerpo como "constitutivo formal" de todo viviente en la filosofía de Schopenhauer", THÉMATA, Revista de Filosofía, Sevilla, núm. 44, p. 437. A su vez, la relación del cuerpo con la voluntad de vivir individuada es tal que en múltiples ocasiones el filósofo alemán los afirma como una única y misma cosa: "No solo las acciones del cuerpo sino también este mismo es, como antes se mostró, fenómeno de la voluntad, voluntad objetivada, voluntad concreta: todo lo que en él sucede tiene que suceder por voluntad, si bien esa voluntad no está aquí guiada por el conocimiento, no se determina por motivos sino que actúa ciegamente por causas que en este caso se denominan estímulos". Schopenhauer, Arthur, El mundo como..., cit., p. 167. Para ahondar en el tema, específicamente sobre las dos maneras en que se da el conocimiento del cuerpo, consúltese el texto de Muñoz-Alonso, Germán, "Reflexiones sobre Schopenhauer y su teoría del cuerpo", Revista general de información y documentación, Madrid, vol. 2, núm. 2, 1992, pp. 93-104. A su vez, sobre la relación entre voluntad y cuerpo en diálogo con Fichte, Vincenzo, Matteo, "Trascendental, cuerpo y voluntad en Fichte y Schopenhauer", en Oncina, Faustino (ed.), Schopenhauer en la historia de las ideas, México, Plaza y Valdés Editores, 2011, pp. 141-164.

20 A su vez, sobre la importancia de este concepto en el pensamiento schopenhaueriano, cómo este principio fundamenta el egoísmo en los hombres y, además, sobre su relación con la Escolástica, consúltese Koßler, Matthias, "El principium individuationis en Schopenhauer y la Escolástica”, en Oncina, Faustino (ed.), Schopenhauer en la historia de las ideas, México, Plaza y Valdés Editores, 2011, pp. 19-40. 
dividuación (principium individuationis) de la individualidad, la cual fundamenta la personalidad de cada individuo:

El principio de individuación se refiere a un principio por el cual, a través de las formas del entendimiento, básicamente espacio y tiempo, la voluntad homogénea se concreta en la pluralidad de lo existente. El principio de individualidad es aquel principio por el cual se hace posible lo real. ${ }^{21}$

La problemática moral inicia precisamente en el momento en que los individuos convergen, pues al encontrarse se ponen en frente afirmaciones distintas de la voluntad de vivir. Estas afirmaciones son, a su vez, cuerpos que se juntan y se interrelacionan; de esta forma, ambas afirmaciones son fuerzas que propenden por la preservación del cuerpo al que pertenecen. En esta interacción entre afirmaciones de voluntades, es posible que alguna de ellas vaya más allá de los límites de su autoafirmación. El determinante que da Schopenhauer para definir este límite no parece ser otro que la afirmación de otras voluntades; es decir, los límites de la afirmación de una voluntad individuada se encuentran entre los límites de las afirmaciones de las otras voluntades individuadas. Ir más allá de estos límites implica necesariamente la negación de la afirmación de otra u otras voluntades. De donde surge la pregunta: ¿cómo se conocen estos límites? La respuesta se encuentra en el sufrimiento. Es este sentimiento el que permite conocer directamente $-\mathrm{y}$ no en abstracto- el ser víctima de una injusticia. Un ejemplo de esto es el caso de la lesión física. Cuando un individuo hiere o golpea a otro, sea cual sea su fin - a menos de que se esté defendiendo de una injusticia-, está afirmando su voluntad de vivir sobre la voluntad de vivir del otro, llegando a negar esa afirmación de la voluntad en el otro. Como se verá más adelante, la mentira y en canibalismo son las afirmaciones de la voluntad que más sobrepasan estos límites y niegan, incluso rotundamente como en el segundo, la afirmación de la voluntad del otro.

Es en este contexto en donde el concepto de injusticia toma relevancia: toda afirmación de la voluntad de vivir que vaya más allá de

21 Cabos, Jordi, “Sufrimiento e individualidad en Schopenhauer”, Anuario Filosófico, Navarra, vol. 47, núm. 3, 2014, p. 591. 


\section{EDWARD DUVÁN OROZCO PEREIRA}

sus límites y, por ende, implique la negación de otras voluntades, es injusta. De esta manera, toda extralimitación de la afirmación de la voluntad de vivir en un cuerpo a través de la negación de la afirmación de la voluntad de vivir manifestada en otro cuerpo es una injusticia. El autor alemán la define como "la irrupción en los límites de la afirmación de la voluntad ajena". ${ }^{22}$ Esto implica que las fuerzas del cuerpo, que normalmente suelen propender por su preservación, cuando un individuo padece una injusticia, son obligadas a usarse a favor de una voluntad ajena a la de su propio cuerpo: a favor de una voluntad dominante.

Schopenhauer afirma que la injusticia no se manifiesta en los hombres de forma abstracta a través de razonamientos - tal y como se concibe en un estudio filosófico-. Por el contrario, su manifestación se da directamente en los individuos como un sentimiento. Por supuesto, este varía dependiendo del lado en el que se encuentra el individuo en la injusticia. El victimario siente la negación de la voluntad en el otro como remordimiento de conciencia ${ }^{23}$ o el sentimiento de la injusticia cometida. La víctima, por su parte, experimenta la irrupción y la negación de su voluntad como un sufrimiento tanto físico como espiritual ${ }^{24}$ :

22 Schopenhauer, Arthur, El mundo como..., cit., p. 393.

23 Schopenhauer parte de que esto necesariamente es así en todos los individuos: "Al contrario que Rousseau, para quien culpa y responsabilidad pueden andar cada una por su lado, Schopenhauer piensa que los remordimientos por un sufrimiento infligido a otro constituyen una piedra de toque fundamental para compulsar nuestro comportamiento ético, el cual no consiste sino en hacernos responsables de todos aquellos actos que tengan una significación moral, subrayando, eso sí, el hecho de que, con ello, estamos respondiendo de aquello que realmente somos" Aramayo, Roberto, "Culpa y responsabilidad como vertientes de la conciencia moral”, Isegoría, Madrid, núm. 29, 2003, p. 30.

24 Es importante aclarar que este no es necesariamente el mismo en todas las víctimas. Contrario a esto, depende de la personalidad de cada sujeto. Al respecto afirma Cabos: "Más que cualquier circunstancia o acontecimiento externo, lo que uno es resulta definitivo a la hora de sufrir. La personalidad no sólo determinará el grado y la intensidad de los padecimientos, sino que además influirá sobre la posibilidad de sufrir algún desajuste mental". Cabos, Jordi, "Sufrimiento e individualidad..., cit., p. 599. 
Esa irrupción en los límites de la afirmación de la voluntad ajena ha sido conocida claramente desde siempre y su concepto se ha designado con la palabra injusticia. Pues las dos partes la conocen instantáneamente, aunque no en una clara abstracción, como aquí nosotros, sino como sentimiento. ${ }^{25}$

El filósofo alemán diferencia dos tipos de injusticia según la causalidad involucrada en su ejecución: las injusticias físicas y las injusticias por medio de la astucia:

Las injusticias físicas son denominadas así debido a que implican un uso de la fuerza corporal para su realización. Schopenhauer propone una gradación al interior de este tipo de injusticias: en su cúspide se encuentra la peor de las injusticias físicas posibles, el canibalismo. En orden descendente, se encuentra a continuación el asesinato, la mutilación o lesión, la esclavitud y, por último, el daño a la propiedad privada moralmente fundada.

Es en este punto donde entran en discusión los conceptos propuestos para ser estudiados en esta investigación. Al partir de estos la pregunta que surge es ¿cuándo la propiedad está moralmente fundada? Schopenhauer fundamenta moralmente la propiedad privada a partir de su relación con otro de los conceptos cruciales en nuestra investigación: el trabajo.

Para Schopenhauer, en el trabajo se unen e identifican las fuerzas del hombre en la búsqueda de un objetivo. Aquí se debe entender el término trabajo más allá de su comprensión en un contexto laboral contractual - si bien es un aspecto que se tendrá en cuenta en su momento- y comprender este concepto como toda actividad en la cual un individuo aplica sus fuerzas para lograr un determinado fin o producto. Para el filósofo alemán, la propiedad privada no puede fundamentarse en la posesión legítima, autoproclamada e instaurada por un individuo. Contrario a esto, debe fundamentarse - al menos en su origen - necesariamente en la adquisición y la apropiación mediante el empleo de sus propias fuerzas, en el mejoramiento y la preservación de las cosas apropiadas mediante su trabajo. Esto es, que el fundamento de la propiedad es el trabajo propio. Por esta

25 Schopenhauer, Arthur, El mundo como..., cit., p. 393. 


\section{EDWARD DUVÁN OROZCO PEREIRA}

razón, el uso de las fuerzas de un cuerpo ajeno en la consecución de un fin o bien de otro cuerpo "hace así que sea el cuerpo del otro en lugar del suyo el que sirva a su voluntad, y afirma su propia voluntad más allá de su fenómeno, hasta llegar a la negación del ajeno: es decir, comete injusticia". ${ }^{26}$ Y, dado que existen objetos que no son susceptibles de mejora o protección, la propiedad sobre estos no puede tener ningún origen moralmente válido. ${ }^{27}$ Estas afirmaciones conducen a Schopenhauer a la conclusión de que todo apropiarse de lo obtenido por medio del trabajo de otro es un acto, en esencia, injusto.

Además de la injusticia física que fue expuesta, existe la injusticia realizada a través de la astucia. En este caso, la causalidad que se encuentra es diferente de su correspondiente física; en esta última se impone la superioridad de una fuerza sobre otra. En la injusticia por astucia, la causalidad ejercida es la del conocer, que se manifiesta en la motivación y que se materializa en el comportamiento de los individuos. Quien obra injustamente a través de la astucia falsea el conocimiento de los demás individuos con mentiras para convencerlos de actuar y servir a su voluntad mientras estos piensan que sirven a la propia. La peor de las injusticias que de este tipo se puede cometer está en el incumplimiento de un contrato, ${ }^{28}$ concepto que se analizará con mayor detalle en el siguiente capítulo y que Schopenhauer recalca cuando afirma:

Pero la más perfecta mentira es el quebrantamiento de contrato; porque aquí todas las determinaciones citadas se dan plena y claramente unidas. Pues al aceptar un contrato, la prestación ajena prometida es inmediata y declaradamente el motivo para que se dé la mía. Las promesas se intercambian deliberada y formalmente. Pero se asume que la verdad de la declaración que se hace se encuentra en poder de cada uno. Si el otro quebranta el contrato me ha engañado y ha guiado mi voluntad conforme a sus propósitos introduciendo en mi conocimiento meros

26 Schopenhauer, Arthur, El mundo como..., cit., p. 395. Las itálicas pertenecen a la fuente citada.

27 A excepción de la que promulga el Estado, asunto que se verá más adelante.

28 Aunque Schopenhauer en El mundo como voluntad y representación no ofrece una gradación detallada similar a la expuesta en el caso de la injusticia física. 
motivos aparentes; ha extendido el dominio de su voluntad hasta el individuo ajeno, así que ha cometido una completa injusticia. ${ }^{29}$

La argumentación expuesta hasta el momento permite vislumbrar un aspecto importante del concepto de justicia estudiado en la obra del filósofo alemán. Este concepto, a diferencia del abordaje realizado por muchos de sus predecesores, no es el originario en la dualidad que forma con su opuesto, la injusticia. Contrario a esto, el concepto de justicia es el derivado y negativo del de injusticia. En palabras de Schopenhauer:

De hecho, nunca se podría hablar de justicia si no existiera la injusticia. En efecto, el concepto de justicia contiene la simple negación de la injusticia y en él se subsume toda acción que no sobrepasa los límites antes señalados, es decir, que no constituye una negación de la voluntad ajena para afirmar con más intensidad la propia. ${ }^{30}$

Esto implica que la determinación de lo justo está, a su vez, en la determinación de aquello que no es una irrupción en la esfera corporal de otro; es decir, el actuar justo se determina siempre desde los límites que no deben violarse en orden a respetar la afirmación de la voluntad del otro y no sobreponer la voluntad propia sobre esta, por lo que lo justo siempre se determina desde aquello que es considerado injusto.

Esta determinación del obrar justo contiene, a su vez, la determinación de la justicia de los actos injustos que responden a una injusticia. Para Schopenhauer, cuando un individuo trata de cometer alguna injusticia sobre otro (esto es, cuando trata de afirmar su voluntad violando sus límites a través de la negación de la voluntad de su víctima), la víctima tiene el derecho de intentar negar la voluntad del victimario. El obrar de la víctima en estos casos, incluso cuando sus actos implican la muerte del otro individuo, es justo en cuanto busca afirmar su voluntad no sobre la voluntad del otro sino sobre su preservación; esto es, dentro de sus límites.

Ibidem, p. 397.

$30 \quad$ Ibidem, p. 398. 


\section{EDWARD DUVÁN OROZCO PEREIRA}

Es así como se puede afirmar que el derecho de coacción para el filósofo alemán surge de la necesidad de los individuos de responder y obligar a cualquiera que intente hacerlo víctima de un obrar injusto, a detenerse y evitar el padecimiento de la injusticia. Esta fundamentación moral de la defensa propia se extiende no solo al uso de la fuerza, sino que, de ser necesario, el individuo puede usar su astucia para afirmar su voluntad a través de la evasión del acto injusto que sobre él quiere recaer. En este caso no desde una causalidad física, como sucedería en el uso de la fuerza, sino desde una causalidad del conocimiento, a través de la motivación:

Así pues, a la voluntad ajena que niega mi voluntad tal y como se manifiesta en mi cuerpo y en la aplicación de sus fuerzas a su conservación sin negar cualquier voluntad ajena que se mantenga en los mismos límites, puedo sin injusticia obligarle a que desista de su negación: es decir, tengo derecho de coacción. ${ }^{31}$

Es decir, la violencia o la astucia de una voluntad se justifican moralmente si por medio de ellas se repele un acto injusto previo. En este sentido, si la usurpación de la propiedad y el trabajo es injusta, entonces sería justa una reacción violenta o astuta para enfrentarse a tal usurpación.

\section{EL CONTRATO EN EL PENSAMIENTO DE SCHOPENHAUER}

Como se mencionó anteriormente, la peor de las injusticias por astucia que se puede cometer está en el incumplimiento de un contrato, ya que la legalidad y la validez del contrato está siempre en no extender la voluntad propia por encima de la del otro por medio de la mentira con el fin de sacar provecho de su fidelidad y honradez:

En esta misma línea, destaca Schopenhauer, como ya adelantamos, que la mentira es el componente fundamental de la doble injusticia o traición, uno de los peores crímenes que cataloga en su teoría del derecho, pues no sólo se actúa contra alguien, sino contra alguien a quien se le había prometido lealtad. ${ }^{32}$ 
Estos dos últimos conceptos, fidelidad y honradez, son de gran importancia para Schopenhauer, ya que se configuran como el lazo que trata de unir la fractura que ocasionó el principio de individuación y que causa, a su vez, el egoísmo natural de cada individuo. Aprovecharse de la presencia de estos dos aspectos en los otros individuos y engañarlos no solo los aleja más entre ellos, sino que causa una injusticia que para Schopenhauer es mucho más ignominiosa que aquellas que se ejercen a través de la fuerza.

El filósofo alemán considera que este tipo de injusticias son más deshonrosas que las físicas, precisamente porque aquellas realizadas por astucia requieren para su ejecución el convencimiento por parte del victimario hacia la víctima de que él es una persona fiel y honrada. Convencer a la víctima de que este individuo tiene estas características es necesario para que el victimario pueda persuadir efectivamente al otro de actuar de determinada manera en la que optará por bienes que injustamente beneficiarán al victimario y no a la víctima. Es precisamente el hecho de convencer a otro de algo que no es cierto - de que se es fiel y honrado- lo que Schopenhauer considera como una grave ignominia.

La importancia de la verdad al interior de los contratos es algo que no solo se observa en Schopenhauer. Es más, esta es un elemento fundamental en cualquier acuerdo existente, ya que en la presunción de que el otro no faltará a su palabra y, por ende, no romperá las promesas que ha acordado es que la sociabilidad se hace posible y sostenible. Este aspecto lo destaca Botero cuando reconoce la importancia de la verdad en la generación de confianza al interior del trato entre los individuos:

En este sentido, el que respeta su palabra y más aún su voluntad jurada genera, por ser oración realizativa, 'confianza' ante sí mismo, ante el otro - al mostrarse como un ser coherente que posibilita así lo socialy ante el lenguaje. Así, evita la 'farsa' de la palabra propia de quien hace, gracias a su 'egoísmo', un mero uso instrumental del discurso. ${ }^{33}$

Schopenhauer, tesis de doctorado, Valencia, Universitat de València, 2012, p. 364.

33 Botero, Andrés, Jurar y juzgar. Estudio sobre el juramento procesal y su evolución en Colombia, siglo XIX, Bucaramanga, Universidad Industrial de Santander, 2019, p. 28. 
Su rol no se limita al plano de la interacción personal entre dos individuos, Botero incluso afirma que la importancia de mantener lo prometido en los juramentos trasciende al plano de las interacciones más generales en la sociedad. Esto, por supuesto, trae al estudio los problemas que surgen de la presencia de la mentira en la degradación de las sociedades:

De allí que este moralista castellano, Valdés, terminase por sugerir, para bien del alma y de la sociedad misma: "Sei tan amigo de verdad, que se dé más fe a tu simple palabra que a juramento de otros"; en sintonía con Vives: "Si te tienen en opinión de verdadero, más creerán una cosa cuando hicieres de cabeza señalando que es así, que si otro con grandísimos juramentos la afirmase". De lo contrario, el perjuro no solo arrastra el alma consigo, sino también a la sociedad, tema sobre el que Vives pone ejemplos históricos de Grecia y Roma. ${ }^{34}$

Además, para Schopenhauer, los conceptos antes mencionados, justicia e injusticia, solo tienen validez en la moral. Su íntima relación con los sentimientos de cada individuo en su respectiva posición ya sea víctima o victimario, imposibilitan su inserción completa en cualquier norma positiva. Contrario a esto, el significado moral de lo justo e injusto es el contenido del derecho natural o moral y tiene una estrecha relación con la conciencia, entendida como autoconocimiento de la propia voluntad individual. La característica fundamental para Schopenhauer a este respecto está en la diferencia entre el objeto de referencia de los derechos: mientras el derecho natural o moral se centra en el actuar de los individuos, en su obrar, el derecho o ley positiva refiere su contenido siempre en relación con la prevención del padecimiento de la injusticia. De tal manera que el derecho positivo estudia el padecer de lo injusto para determinar qué se puede hacer justamente o qué actos u obrar puede considerarse justo realizar siempre en búsqueda de no ser víctima de injusticias; es decir, de evitar el padecer. Lo que implica, entonces, que el derecho se hace pensando en el inmoral, en el que obra injustamente y no en el comportamiento justo o moral por sí mismo.

34 Ibidem, p. 48. 
Esta búsqueda se enmarca en un ejercicio racional por parte de los individuos en el que reconocen que existe una proporción directa entre el sentimiento de placer que genera la injusticia en el victimario y el de sufrimiento que experimenta la víctima. Este reconocimiento lleva a los individuos a buscar la disminución del sufrimiento a través de la renuncia al placer de causar injusticia y esta búsqueda, precisamente, configura para Schopenhauer el verdadero fundamento del contrato social o ley positiva: "Así pues, ese medio que el egoísmo ideó fácilmente y fue poco a poco perfeccionando cuando por el uso de la razón procedió metódicamente y abandonó su punto de vista unilateral, es el contrato social o la ley". ${ }^{35}$

Es de esta manera como la teoría política ${ }^{36}$ y la doctrina de la legislación - en términos de Schopenhauer - se refieren a la prevención del padecimiento de la injusticia mas no al obrar justo. De esta forma, el derecho (es decir, el juez) castiga no porque busque la justicia, sino porque busca atemorizar a los individuos, a través del efectivo castigo a los condenados, para que no sometan a actos injustos a los demás. Así, las normas prohíben ciertos actos porque su fin es evitar y prevenir el padecimiento de la injusticia, mas no porque busquen el obrar justo en sí mismo. Aquí la argumentación del filósofo alemán recae en la individualidad de la moral: la injusticia cometida lo es siempre en relación con la voluntad de cometer

35 Schopenhauer, Arthur, El mundo como..., cit., p. 403.

36 Al respecto es importante recalcar que Schopenhauer defiende la monarquía hereditaria como la menos peor de las organizaciones políticas posibles y, por ende, la mejor. Mateu identifica al menos cinco argumentos que usa el filósofo alemán en su defensa ante el republicanismo: i) la imposibilidad del derecho moral de aplicarse en la realidad social por fuera de las instituciones tradicionales propias de la monarquía, ii) el fomento de las artes y las ciencias más propio de las monarquías, iii) la apelación a un naturalismo jerárquico en el cual la monarquía sería una manifestación suya y el republicanismo un movimiento contranatura, iv) la necesidad de la existencia de la esclavitud (institución que rechaza Schopenhauer por ser una injusticia física) en el republicanismo y, por último, v) la existencia de una mayor estabilidad política en las monarquías que en las repúblicas. Se recomienda la lectura del texto de Mateu, Juan, La filosofía política..., cit., pp. 340-342, especialmente por la contrargumentación que realiza sobre los cinco argumentos que se mencionaron anteriormente. 
EDWARD DUVÁN OROZCO PEREIRA

injusticia. ${ }^{37}$ Para el Estado, por el contrario, lo injusto está relacionado con la acción solo en la medida en que tiene como correlato el sufrimiento o padecimiento de la injusticia. Por esta razón, el Estado no prohíbe ni pretende prohibir el deseo de cometer injusticia, solo intenta, a través de contramotivos, como las penas, evitar que las razones que llevan a los individuos a actuar injustamente se materialicen:

Tampoco tiene el Estado en modo alguno el necio plan de exterminar la inclinación a la injusticia, los sentimientos malvados, sino que simplemente pretende, con el inevitable castigo, poner al lado de cada posible motivo para cometer una injusticia otro preponderante para abstenerse de ella: según eso, el código penal es un registro tan completo como sea posible de los contramotivos para todas las acciones criminales que se presumen como posibles, ambos formulados in abstracto para aplicarlos in concreto a los casos que se presenten. ${ }^{38}$

El derecho positivo entonces, en relación con la moral, se mueve en sentido inverso: mientras la moral se centra en el aspecto activo (es decir, en el cometer, en las acciones de cada individuo y a través de estas busca los límites de la definición del actuar justo), el derecho positivo se centra en el aspecto pasivo (en el padecimiento y busca así determinar los límites del comportamiento en orden a que los individuos que hacen parte de su sociedad no sufran injusticias a futuro).

37 Al respecto, consúltese el texto de Aramayo, en donde profundiza más en la responsabilidad y la pena en el filósofo alemán. Al respecto afirma el filósofo alemán: "Si desnudamos a esa presentación kantiana de aquella dramaturgia jurídica con que la ha investido arbitrariamente, se disipa también el halo que la rodea junto a su majestuoso efecto y sólo queda el escueto hecho de que, al reflexionar sobre nuestras acciones, a veces nos asalta un descontento con nosotros mismos de índole muy peculiar, el cual tiene la peculiaridad de no concernir al resultado, sino a la acción misma, y de no descansar en razones egoístas, como sí lo hacen todas aquellas en que lamentamos la imprudencia de nuestro obrar. Nosotros estamos insatisfechos con nosotros mismos por un sufrimiento que no hemos padecido, sino causado; éste es el hecho desnudo y que nadie negará”, Schopenhauer citado en Aramayo, Roberto, “Culpa y responsabilidad..., cit., p. 30.

38 Schopenhauer, Arthur, El mundo como..., cit., p. 404. 
Lo anterior aclara el rol y la función del Estado, pues este no se dirige a modificar o perfeccionar la moralidad de cada individuo, ya que, para el filósofo alemán, esto no es posible, pues el origen del Estado se encuentra en la respuesta al egoísmo y a las consecuencias perjudiciales de este último. De tal manera, que el fin primero del Estado - en congruencia con lo expresado por Hobbes-, ${ }^{39}$ es el bienestar público mediante prohibiciones respaldadas por castigos:

Como se dijo, el Estado no está dirigido contra el egoísmo en general y en cuanto tal; muy al contrario, ha nacido del egoísmo de todos que se comprende a sí mismo, procede de manera metódica y pasa del punto de vista unilateral al general haciéndose así común por acumulación; solo para servir a este existe el Estado, erigido bajo la correcta hipótesis de que no se puede esperar una moralidad pura, es decir, un obrar justo por razones morales; en otro caso, él mismo seria superfluo. ${ }^{40}$

La legislación positiva (las normas vigentes), en relación con lo antes mencionado, es la doctrina moral del derecho aplicada por el lado inverso. Lo que implica entonces que un verdadero derecho positivo, para lograr conformar un Estado como una legítima asociación de derecho, debe estar determinado fundamentalmente por las directrices de la doctrina pura del derecho moral o derecho natural: "solo entonces es la legislación un verdadero derecho positivo y el Estado una asociación de derecho, un Estado en el sentido propio de la palabra, una institución moralmente lícita y no inmoral". ${ }^{41}$ Luego, de la relación del derecho positivo y el natural de una sociedad depende la perfección del Estado, su legitimidad y justicia.

El contenido de toda doctrina pura del derecho o derecho natural debe realizar cinco tareas que fundamentarán su contenido, tales son: a) explicar el significado verdadero y el origen del concepto de justo e injusto; $b$ ) deducir el derecho de propiedad y su validez moral; c) deducir la validez moral de los contratos (fundamentación moral del derecho contractual); d) explicar el nacimiento y la finalidad del Estado y su relación con la pura doctrina del derecho; y, por

39 Esto lo reconoce Schopenhauer en su texto, ibidem, p. 405.

40 Idem.

41 Ibidem, p. 406. 


\section{EDWARD DUVÁN OROZCO PEREIRA}

último, e) deducir el derecho penal a partir de la finalidad del Estado y su relación con la moral.

El término doctrina pura del derecho o derecho natural hace referencia al contenido moral de todo derecho natural o moral posible, alejado de su equivalente positivo que se fundamenta única y exclusivamente en la prevención del padecimiento de injusticias. Difiere radicalmente de este en que sí se dirige hacia el actuar justo del hombre, hacia qué debe hacer cada individuo para ser justo. Además de esto, determina al menos tres aspectos fundamentales - que se mencionan en el párrafo anterior- de la vida en sociedad: el derecho de propiedad, el Estado y el derecho penal.

Hasta el momento se han dilucidado los cuatro primeros puntos de la determinación del contenido de la pura doctrina del derecho moral. Así, para finalizar, el derecho penal se encarga, principalmente, de coaccionar a los individuos de la sociedad en la renuncia del placer del cometer la injusticia y, ante todo, de evitarle a los ciudadanos el sufrimiento de injusticias en el futuro por medio de la prevención general negativa ${ }^{42}$ (se sanciona a alguien para que sirva como ejemplo a los demás). Esta normativa solo puede darse al interior del Estado como ley positiva, es decir, como definición siempre previa de un castigo relacionado con un crimen. Esto implica que todos los miembros de la sociedad, en pleno conocimiento de estas leyes, reconozcan, acepten y cumplan los mandatos allí expresados. ¿Y cómo se logra esto? Como se mencionó previamente, debe lograrse por medio de la pena o la sanción, puesto esto sirve de ejemplo a todos para que así se abstengan de cometer un acto injusto por miedo (aspecto que une a Schopenhauer con la tradición hobbesiana sobre la función del miedo en la organización política). ${ }^{43}$

42 Se ve aquí un rasgo que se puede identificar con la teoría de la prevención general: el único fin legítimo de la pena es infundir miedo en los demás a través de su efectiva ejecución y así prevenir que se cometan más injusticias. En palabras de Schopenhauer: "Por eso el Estado no prohibirá a nadie que piense continuamente en matar y envenenar a otro, en cuanto sepa con certeza que el miedo a la ejecución y al suplicio impedirá los efectos de aquel querer". Ibidem, p. 404.

43 Idea que luego se presenta en Olivecrona (1987-1980), quien "Define el derecho como una fuerza (que ejerce presión psicológica verificable experimentalmente pero, a veces, debe recurrir a la fuerza física para terminar de respaldar la 
Sobre este punto es importante mostrar la relación que tiene la postura del filósofo alemán con la teoría de la prevención general. Para esta teoría el único fin de la pena es la intimidación, a través del castigo, de la generalidad de los ciudadanos con el fin de que no comentan ningún crimen:

El delincuente, para esta posición, es un hombre que atenta contra el sistema adoptado por la generalidad, y dicho acto dañino, socialmente merece ser reprimido con tal que sirva de lección a los miembros de la sociedad, amenazándolos con la imposición de penas similares si copian la conducta del castigado. ${ }^{44}$

Así, se ve aquí un rasgo que se puede identificar de la teoría de la prevención general en el pensamiento del filósofo alemán: el único fin legítimo de la pena es infundir miedo en los demás a través de su efectiva ejecución y así prevenir que se cometan más injusticias. En palabras de Schopenhauer: "Por eso el Estado no prohibirá a nadie que piense continuamente en matar y envenenar a otro, en cuanto sepa con certeza que el miedo a la ejecución y al suplicio impedirá los efectos de aquel querer". ${ }^{45}$

El reconocimiento, la aceptación y el cumplimiento de estas leyes implica la creación y la instauración de un contrato en el que los individuos renuncian al placer de la injusticia para beneficiarse del no padecimiento de injusticias. Lo cual, en relación con lo que se ha mencionado anteriormente respecto de la importancia moral de los contratos, nos lleva a deducir un aspecto importante acerca de la moralidad del derecho contractual. El incumplimiento de un contrato implica el uso de la astucia para tornar las fuerzas de la voluntad de otros individuos al servicio de la propia. De tal manera que el

presión psicológica de obedecimiento en los miembros de la comunidad, esto es, actualizar el miedo al castigo) pero organizada burocráticamente y por reglas jurídicas que son habitualmente respetadas por la población, logrando así la convivencia y el bienestar social", Botero, Andrés, "El positivismo jurídico en la historia: las escuelas del positivismo jurídico en el Siglo XIX y primera mitad del Siglo XX", en Fabra, Jorge (ed.), Enciclopedia de filosofía y teoría del derecho, México, UNAM, 2015, p. 148. La información en el corchete es propia.

44 Botero, Andrés, "La teoría unificadora dialéctica de Roxin a la luz de Beccaria”, Revista de Derecho Penal, Madrid, núm. 25, 2001, p. 100.

45 Schopenhauer, Arthur, El mundo como..., cit., p. 404. 
incumplimiento del contrato social aceptado por cada individuo en su adhesión a una sociedad no solo es un ilícito desde una perspectiva meramente jurídica, sino un acto injusto inmoral en total independencia de la coherencia entre el derecho positivo y la pura doctrina moral del derecho. Es decir, que incluso en los casos en que lo castigado por el derecho positivo no es considerado un acto injusto desde la moral, el delito o el ilícito cometido, según el caso, pasa a ser la injusticia más ignominiosa que pueda cometer un individuo en la medida en que incumple un contrato que él conscientemente ha aceptado. Esto implica que todo delito o crimen cometido es por sí mismo el quebrantamiento de un contrato, específicamente de aquel que el hombre ha aceptado para vivir en sociedad y en el que se comprometía a dejar de lado su egoísmo con el fin de lograr una vida en comunidad libre del padecimiento de injusticias.

\section{CONDICIONES DE UN CONTRATO DE TRABAJO JUSTO \\ EN EL PENSAMIENTO MORAL DE ARTHUR SCHOPENHAUER}

Para contestar la pregunta propuesta en esta investigación, a saber, ¿en qué condiciones un contrato de trabajo es justo o injusto desde el pensamiento moral de Arthur Schopenhauer?, se deben retomar y profundizar algunos aspectos mencionados anteriormente.

El primero de ellos es el relacionado con la propiedad. Se afirmó previamente que, en su origen, solo hay un fundamento moral de la propiedad privada: la adquisición y la apropiación mediante el empleo de las propias fuerzas. Sin embargo, además del trabajo, existen otros dos tipos de fundamentos morales: la transferencia (entre individuos) y el otorgamiento por parte del Estado. En el primer caso, se encuentra la permuta y la donación; ${ }^{46}$ y, en el segundo, la cesión voluntaria y la recompensa.

46 Una tercera ubicada aquí es la herencia. Schopenhauer no la menciona en El mundo como voluntad y representación, pero en otras obras lo introduce como un fundamento legítimo de la propiedad: "En las lecciones sobre metafísica del derecho, Schopenhauer introduce una modificación al texto de WWV, I, §62, mediante la que intenta legitimar el derecho de herencia por el derecho absoluto de propiedad; si la propiedad, moralmente legítima, es una cosificación mediada por las fuerzas 
Sin embargo, al analizar el fundamento moral originario (el trabajo) se comprende que, como bien lo menciona Battaglia, ${ }^{47}$ este es un concepto que encierra en sí mismo varios significados. Al interior del trabajo como fundamento originario de la propiedad, radican en Schopenhauer varias actividades que entran en este significante: el mejoramiento, la protección, la elaboración y la conservación. Esto supone un problema, ya que, si se parte de que estas actividades en el caso de cualquier objeto producido y, por ende, apropiado, ${ }^{48}$ son realizadas por distintos individuos, ¿quién debe ser el legítimo propietario de este objeto? Schopenhauer, si bien parece haberse planteado este interrogante, no profundiza en detalle en su resolución. Lo que se encuentra en El Mundo como Voluntad y Representación es una afirmación que posibilita construir una respuesta:

En efecto, cuando a través de un esfuerzo ajeno, por pequeño que sea, una cosa es elaborada, mejorada, protegida frente a los accidentes o conservada, aunque ese esfuerzo consistiera simplemente en recoger o levantar del suelo una fruta silvestre, está claro que el que arrebata tal cosa quita al otro el resultado de las fuerzas empleadas en ella, hace así que sea el cuerpo del otro en lugar del suyo el que sirva a su voluntad, y afirma su propia voluntad más allá de su fenómeno, hasta llegar a la negación del ajeno: es decir, comete injusticia. ${ }^{49}$

del propio individuo, de su voluntad, el individuo posee un derecho total sobre la propiedad, lo que incluye la cesión hereditaria”. Mateu, Juan, La filosofía política..., cit., p. 349.

47 Afirma Battaglia sobre la definición del trabajo: "Trabajo es un concepto complejo, ya que hace relación a los más diversos aspectos de la vida, y por ello considera a las ciencias más diversas, cada una de las cuales se ocupa de él y lo encuadra diversamente, más o menos, central, más o menos importante, pero siempre digno de interés" Battaglia, Felice, Filosofía del trabajo, trad. de Francisco Elías de Tejada, Madrid, Editorial Revista de Derecho Privado, 1955, p. 7.

48 Se prefiere este término al de poseído, por tener este entre sus significados uno que Schopenhauer descartará enfáticamente y es el de la cosa que alguien ha declarado ser su posesión: "Porque es claro y fácil de ver que no puede haber una toma de posesión legítima sino solamente legítima adquisición, apropiación de la cosa mediante el empleo originario de las propias fuerzas en ella" Schopenhauer, Arthur, El mundo como..., cit., p. 395. Las itálicas son parte de la fuente citada.

49 Idem. 
Así, con base en lo anterior, la respuesta a la pregunta lleva a que se plantee una propiedad compartida. El objeto en el que se hayan aplicado las fuerzas de varios individuos tiene que, necesariamente, ser propiedad de todos aquellos sujetos que aplicaron sus fuerzas en el mismo. Esto, por supuesto, conduce a otra pregunta: ¿cómo se determina la proporción de propiedad que cada uno de estos individuos tiene sobre esa cosa? No se tienen elementos suficientes para contestar esta pregunta, de manera estricta ${ }^{50}$, desde esta obra de Schopenhauer. Sin embargo, se proponen dos posibles salidas congruentes con su pensamiento. Por una parte, en el caso en el que la cosa apropiada pueda dividirse, la distribución de esta propiedad entre sus copropietarios se daría de manera justa entre ellos si ninguno de estos siente que está padeciendo injusticia en ese acuerdo. De esta manera, el determinante que permite saber si esta división es justa o no es, en última instancia, la voluntad de cada uno de los individuos y, particularmente, la ausencia del sufrimiento propio del padecimiento de una injusticia.

Por otra parte, una salida alternativa se puede encontrar en uno de los otros fundamentos morales de la propiedad antes enunciado: la permuta. Esta entendida como una transferencia de propiedad bidireccional. En este caso, los copropietarios pueden intercambiar objetos entre ellos para facilitar la distribución siempre teniendo como criterio que ninguno de los individuos copropietarios sienta que los demás están negando su voluntad de vivir manifestada en las fuerzas aplicadas en el objeto.

En cualquiera de los dos casos deberá haber un acuerdo entre todos los individuos involucrados y, por ende, será necesario un contrato. De esta forma, por el respeto que merece la fidelidad y la honradez de todos los individuos y la búsqueda de la justicia, deberá excluirse de este acuerdo cualquier tipo de mentira o astucia que intente falsear el conocimiento de los demás con el fin de que en su comportamiento actúen a favor de la voluntad de otro individuo mientras piensan - y no es así- que benefician la suya.

50 Mucho más si tiene en cuenta el estilo de Schopenhauer. Al respecto, consúltese Rábade, Sergio, "El cuerpo en Schopenhauer", cit., p. 139. 
La donación no parece ofrecer problemas para la moral. Al ser una transferencia unilateral, la responsabilidad recae absolutamente en la decisión voluntaria del propietario de transferirla sin recibir nada a cambio. El fundamento moral de esta transferencia reside en que el propietario de cierto objeto posee derechos sobre el objeto mismo, de la misma forma en la que posee derechos sobre su cuerpo y según Schopenhauer este podrá disponer de su objeto según lo determine:

Tal como lo hemos deducido antes, el derecho de propiedad moralmente fundado da por su naturaleza al propietario un poder sobre la cosa tan ilimitado como el que tiene sobre su propio cuerpo; de donde se sigue que puede transferir su propiedad a otros mediante permuta o donación, y estos entonces poseerán la cosa con el mismo derecho que él ${ }^{51}$.

La cesión voluntaria y la recompensa son las dos últimas formas en las cuales se sustenta la propiedad privada. En este caso, su fundamento se mueve entre lo moral y lo jurídico. Para Schopenhauer, este tipo de justificación solo se aplica a aquellas cosas que no son susceptibles de ser trabajadas por mejoramiento o protección..$^{52} \mathrm{El}$ carácter dual de la posesión de estos objetos queda claro en el siguiente fragmento:

De todo lo que no sea susceptible de ser trabajado por medio de una mejora o una prevención contra los accidentes, no hay ninguna posesión exclusiva moralmente fundada, a no ser que se la posea por una cesión voluntaria de todos los demás o en recompensa por otra clase de servicios; pero esto supone ya una comunidad reglamentada por convención: el Estado. ${ }^{53}$

Lo anterior implica al menos dos contratos: a nivel particular entre un individuo y el Estado; y a nivel más general en la aceptación y la existencia del Estado mismo, quien promulga la ley y con esto

51 Schopenhauer, Arthur, El mundo como..., cit., p. 396.

52 Schopenhauer no ofrece ejemplos sobre este tipo de propiedades. Por lo que queda abierto el interrogante sobre para qué objetos aplicaría en este caso.

53 Idem. 


\section{EDWARD DUVÁN OROZCO PEREIRA}

acepta la existencia de un contrato social que busca la coexistencia sin injusticias de sus ciudadanos.

Para concluir la disertación sobre la propiedad, resulta pertinente ver otras visiones de este concepto enmarcadas fuera de la obra magna de Schopenhauer. Es este el caso de la obra de Juan Mateu titulada La filosofía política y su trasfondo ontológico en la obra de Arthur Schopenhauer, pues allí se exponen aspectos de gran relevancia para esta investigación. En uno de sus trabajos se aborda, precisamente, la relación entre los fundamentos de la propiedad privada y cómo se aplican realmente en la sociedad. Al respecto, Mateu ${ }^{54}$ recalca que para Schopenhauer las propiedades se adquieren - ya en su tiempo- más por la transferencia, es decir, a través de la permuta, la herencia o la donación, que por la adquisición a través del trabajo propio:

Esto es así hasta tal punto que en el mencionado ensayo Sobre el fundamento de la moral, Schopenhauer reconoce que casi ninguna propiedad real responde al derecho moral, es decir, está basada en el trabajo, sino que la mayoría es adquirida, heredada, etcétera, de modo que no puede menoscabarse el derecho positivo a la propiedad por una reivindicación directa de la propiedad como derecho moral basado en el trabajo. ${ }^{55}$

De la información precedente se concluye que, si bien el trabajo es, en origen, el fundamento moral legítimo de toda apropiación de una propiedad, ya en la época del filósofo alemán, es, en realidad, el menos común de los fundamentos de la propiedad privada. ${ }^{56}$ Esta

54 Mateu también realiza una reflexión importante sobre la relación del pensamiento de Schopenhauer con el marxismo y se interna en el debate sobre si el filósofo alemán es o no defensor del capitalismo, tema que también se encuentra en Botero, Andrés, "Schopenhauer: entre el ostracismo y los memes", Revista Filosofía UIS, Bucaramanga, vol. 17, núm. 2, 2018, y Zapata, Daiman, "Arthur Schopenhauer, ¿defensor del capitalismo?”, Versiones, vol. 1, núm. 5, 2014, pp. 25-34.

55 Mateu, Juan, La filosofía política..., cit., p. 347.

56 Esto último se muestra como un ejemplo de lo expuesto por Paolo Prodi en sus obras y que se encuentra sintetizado en Botero, Andrés y Aguirre, Javier, "El juramento y los dos foros: los aportes histórico-filosóficos de Paolo Prodi en relación con el rol de la religión en las democracias occidentales", Tópicos, Revista de Filosofía, México, núm. 57, 2019, pp. 87-123. Al perder el fuero moral la influencia en el comportamiento del hombre, el derecho positivo se apropia de este terreno y lo 
afirmación es fundamental para este trabajo porque permite ir un paso más allá de lo estrictamente expresado por Schopenhauer en El mundo como voluntad y representación y poder tener esta aseveración del filósofo alemán como premisa a la hora de contestar la pregunta rectora de este estudio.

Sin embargo, antes de pasar a esta respuesta, es necesario revisar de cerca un aspecto importante en relación con todo contrato. Como se afirmó previamente, lo más valioso al momento de acordar un contrato es la fidelidad y la honestidad que los individuos se prometen entre sí. De esta forma, cualquier mentira proferida por alguno de los individuos involucrados y que implique una extralimitación de la una voluntad sobre otra es una injusticia. No obstante, si se revisa la visión presente en $\mathrm{Mateu}^{57}$ se comprende que existen al menos cuatro situaciones en las cuales la mentira es justa.

La primera de estas es cuando la mentira es utilizada como medio para evitar ser víctima de una injusticia, como una especie de legítima defensa. Este aspecto de la mentira como acto injusto ya se había estudiado cuando se refirió sobre la justicia de los actos injustos. De este modo, si un individuo percibe que hay otro que intenta hacerlo padecer una injusticia, este puede usar la causalidad física (violencia) o del conocimiento (mentira) para evitar que efectivamente lo haga.

El segundo caso atañe a aquellos momentos en los cuales la intimidad personal y la propiedad privada intentan ser invadidos por la indiscreción de la curiosidad por fuera de los límites de otro individuo. Concretamente en el caso en el que no responder ante las inquietudes del otro o responder con una negativa a dar una respuesta a la pregunta puede generar sospechas en los otros y esto puede llevar al detrimento de sus propiedades o intimidad.

Los dos primeros casos hasta ahora vistos corresponden ambos a un derecho a mentir en situaciones concretas. Sin embargo, el tercero será, ya no un derecho, sino un deber. Para Schopenhauer,

domina a través del miedo generado, no por entes trascendentales (aunque en este caso no esté necesariamente ligado a una deidad), sino por un ente terrenal y por todos conocido, el Estado y su derecho.

57 Mateu, Juan, La filosofía política..., cit. 


\section{EDWARD DUVÁN OROZCO PEREIRA}

hay ciertos casos en los cuales mentir es una obligación de cierto individuo que busca un objetivo que le es beneficioso a otro individuo. El ejemplo que trae Mateu - que a su vez él rescata de Schopenhauer - es el del paciente con síntomas psicofísicos, cuya medicación no tiene realmente un principio activo, pero su consumo inconsciente trae beneficios a su salud. En este caso, es deber del médico mentirle a su paciente sobre la naturaleza del medicamento para que este siga sintiendo los beneficios.

Por último, se presenta en Schopenhauer una defensa de la mentira noble, en la que un individuo se auto-inculpa para evitarle un daño al otro:

Independientemente de los problemas que pueda padecer una posición radicalmente anti-egoísta, como la de Schopenhauer, para la que paradójicamente la acción de mayor valor sea la negación de la propia voluntad, Schopenhauer apunta al ennoblecimiento de la mentira en una situación no excepcional: la falsa auto-inculpación para evitar un daño a otro. ${ }^{58}$

Ahora, al relacionar los casos en los que la mentira es justa para Schopenhauer con la necesidad de fidelidad y honestidad al interior de los contratos, surgen varias preguntas: ¿se aplican algunos de estos casos para los contratos?, ¿o requieren estos de una honestidad absoluta?

Se propone que todos los casos podrían encontrarse al interior de un contrato, y la existencia de alguna de estas mentiras no parece implicar necesariamente su incumplimiento. En el primer caso, aquel que miente para prevenir una injusticia está precisamente evitándola y, con esto, está preservando la justicia al interior del contrato, por lo que su obrar sería justo. Para el segundo caso, la aplicación, al igual que para el primero, parece omnipresente, al privilegiarse la protección a la propiedad privada y la intimidad, el contrato estaría necesariamente subordinado a estos. El tercer caso presenta una situación en la cual al menos uno de los individuos tiene una condición especial (como el paciente con síntomas psicofísicos), y, sin duda, se podría afirmar, desde este caso, que un individuo debe

$58 \quad$ Ibidem, p. 367. 
mentir si esta mentira, en últimas, va a ser beneficiosa para el otro sujeto involucrado en el contrato. ${ }^{59}$ Igual sucedería en el cuarto caso, en donde la auto-inculpación puede traer beneficios para el otro o los otros individuos inmersos en el contrato.

De esta manera se observa que más allá de un rechazo a la mentira al interior mismo del contrato, lo que necesariamente no debe suceder en un contrato justo es precisamente que alguno de los individuos le mienta a los demás con el fin de extraer de esa relación contractual más de lo que le corresponde a costa de lo que le pertenece a cada uno de los demás individuos.

$Y$ es precisamente en relación con esto que el juramento, como acto de acuerdo de un contrato tiene dos funciones fundamentales: por un lado, servir de garantía ante los demás individuos que pactaron el acuerdo y, por el otro, y a partir de este, como posibilitador de todo contrato, en la medida que la existencia de una garantía da cierta tranquilidad a los individuos en relación con su efectivo cumplimiento:

Pero, ¿cuál era la función del juramento? Según Prodi, esta institución garantizaba la armonía y la estabilidad de la vida propia de la colectividad, en la medida en que establecía relaciones duraderas de disciplinamiento social que permitían la convivencia y la paz con las entidades metafísicas a las que se temía por su capacidad de venganza o, por lo menos, a las que se respetaba por su posibilidad de protección. ${ }^{60}$

El último de los conceptos a revisar es el de trabajo. Este tiene al menos dos acepciones a considerar. La primera de ellas hace referencia al trabajo como la actividad de un individuo en la cual él ejerce sus fuerzas en la elaboración, protección, mejoramiento o conservación de un objeto. En esta acepción se excluye, por supuesto, cualquier relación de subordinación, ya que el único fin que se persigue es precisamente el producto mismo de ese trabajo. Estos aspectos presentes en la acepción schopenhaueriana de El mundo

59 Esto a simple vista llega "a un límite abierto a discusión" y a una "polémica casi irresoluble". Mateu, Juan, La filosofía política..., cit., p. 367. No se centrará este apartado en replicar las distintas posturas en la discusión ya que no es, propiamente, el objetivo de este trabajo.

60 Botero, Andrés y Aguirre, Javier, “El juramento y..., cit., p. 103. 


\section{EDWARD DUVÁN OROZCO PEREIRA}

como voluntad y representación se enmarcan en lo expresado por Battaglia cuando afirma:

...tanto denota la forma o la acción general del trabajo (yo trabajo), cuanto la cosa elaborada o producto (este libro es un trabajo mío), y, por fin, el esfuerzo mantenido en la producción, siendo sinónimo de fatiga (grande es el trabajo para conseguir tal o cual calificación en los exámenes). ${ }^{61}$

Sin embargo, por otra parte, y en relación con el objetivo de esta investigación, se tiene que diferenciar el uso de este concepto cuando se refiere a una relación laboral. Aquí, por supuesto, el individuo que aplica sus fuerzas a determinado fin no lo hace por el producto mismo, sino porque ha pactado o contratado con otro individuo que recibirá un bien a cambio de su trabajo. Sobre esta cuestión se debe considerar que, aunque lo adquirido al final de la actividad en ambas acepciones es diferente, la actividad que se realiza, en sí, sigue siendo conforme a la primera acepción, es decir, sigue siendo trabajo, entendido como la aplicación de las propias fuerzas en un determinado objeto. Incluso, se puede sostener que al interior de esta acepción de trabajo como relación laboral tiene que encontrarse el trabajo como actividad del individuo, con la salvedad de que aquel que realiza el trabajo voluntariamente decide intercambiar el producto de su labor por otro bien de otro individuo.

De esta manera, dentro del contrato de trabajo se encuentra, entonces, un acuerdo entre individuos que pactan intercambiar (por transferencia) el producto del trabajo (entendido en la primera acepción mencionada) de uno de ellos por un determinado bien ${ }^{62}$ que el sujeto que ha aplicado sus fuerzas en el mejoramiento, protección, elaboración o conservación del objeto ha aceptado a cambio. Esto lleva a uno de los interrogantes que surgieron al inicio de esta investigación y es ¿cómo puede efectivamente un contrato laboral ser justo desde el fundamento originario de la propiedad, a saber, que solo es justa la propiedad fruto del trabajo propio? La respuesta

62 Que en la gran mayoría de casos suele ser dinero. 
radica, precisamente, en que este tipo de contrato requiere de una fase posterior al origen de toda propiedad privada y necesita enmarcarse en los fundamentos de transferencia o de otorgamiento; es decir, como condición de posibilidad de todo contrato laboral se requiere que se den ya los otros fundamentos distintos al trabajo en su primera acepción.

Esto, a su vez, muestra una diferencia fundamental en las afirmaciones que realiza Schopenhauer en sus obras. Mientras en El mundo como voluntad y representación I se encuentran proposiciones de orden más prescriptivo, es decir, señalando el deber ser de la propiedad; en otros textos como Sobre el fundamento de la moral (texto posterior a El mundo como voluntad y representación I), el filósofo alemán realiza afirmaciones descriptivas sobre el ser de la propiedad privada en su momento. De esto se puede concluir que Schopenhauer era consciente, al menos al momento de publicar esta segunda obra, de que su propuesta sobre el origen de toda propiedad privada era difícilmente realizable, sobre todo si el fundamento de la gran mayoría de las propiedades se encontraba en la transferencia o el otorgamiento, y no en el trabajo propio.

De esta manera, se tienen ya los elementos necesarios para responder a la pregunta rectora de este escrito: ¿en qué condiciones un contrato de trabajo es justo o injusto desde el pensamiento moral de Arthur Schopenhauer? Primero, no deben existir mentiras al interior del contrato, a excepción de aquellas que se enmarquen en los cuatro casos ya mencionados. Segundo, ninguno de los individuos debe sentir, ya acordado el contrato, que es víctima de una injusticia, es decir, no debe padecer ningún sufrimiento. Así, de igual forma, ninguno de los dos sentirá remordimiento de conciencia, ya que no le han infringido ninguna injusticia al otro. Lo que implica, entonces, que ninguno de los dos tenga pretensiones de afirmar su voluntad negando la voluntad del otro. Y esto es posible por, como tercero y último, un concepto fundamental en el pensamiento de Schopenhauer: la compasión. ${ }^{63}$ Esta, para el filósofo, es el fundamento de

63 Concepto que recuerda a la simpatía humeana. Al respecto, consúltese Hume, David, Tratado de la naturaleza humana II, trad. de Félix Duque, Buenos Aires, Orbis, 1984, pp. 441-510. 
toda moral -en contraposición con el egoísmo propio del principio de individuación-y sin el cual toda moral se reduce a un esquema lógico en abstracto:

La "compasión" hace posible romper el estrecho círculo del egocentrismo, para lograr una cierta identificación con el otro. El egoísta considera al mundo como un "no-yo" absoluto y mantiene con él relaciones hostiles, instrumentales o de desconfianza; en cambio, a través de la compasión los otros e incluso lo otro (los seres no humanos y los objetos) deja de ser el "no-yo" para adquirir un carácter de "yo otra vez". La compasión implica un proceso de descentración de la imagen del mundo, que representa un requisito indispensable del punto de vista moral. ${ }^{64}$

\section{CONCLUSIONES}

En búsqueda de la respuesta a la pregunta directriz de esta investigación, ¿en qué condiciones un contrato de trabajo es justo o injusto desde el pensamiento moral de Arthur Schopenhauer?, se plantearon tres momentos correspondientes a cada uno de los capítulos de este texto.

En el primer capítulo, se revisaron los conceptos de injusticia-justicia, propiedad y trabajo, buscando dar claridad sobre sus acepciones desde la perspectiva schopenhaueriana, con el fin de usarlos de forma precisa en la respuesta al interrogante planteado. Para esto fue necesario realizar antes un sintético esquema del término voluntad, sus acepciones en el pensamiento schopenhaueriano y su relación con el cuerpo. En el segundo capítulo se detallaron el concepto de contrato y su aplicación; a su vez, se explicitó su relación con otros conceptos como fidelidad y honradez y, además, se expuso el Estado y el derecho positivo como fundamentados en un contrato, el contrato social. En el tercer capítulo se desarrolló el objetivo principal de esta investigación y, por ende, se dio respuesta a la pregunta planteada. Para eso debió ahondarse minuciosamente en los con-

64 Serrano, Enrique, "Sobre el fundamento de la moral", Signos, Anuario de Humanidades, México, año X, 1996, p. 243. 
ceptos de propiedad y contrato, así como la mentira (astucia) y su importancia, a la vez que fue necesario recurrir a fuentes especializadas que permitieron obtener información más precisa de otras obras de Schopenhauer distintas a su obra magna.

De esta manera, la hipótesis de la que se partió al inicio de la investigación (a saber, que sí puede existir un contrato laboral justo desde Schopenhauer) se confirmó, por lo que a pesar de la tajante afirmación schopenhaueriana de que la propiedad es justa si proviene del trabajo propio debe matizarse con declaraciones posteriores del mismo filósofo que permiten inferir que la propiedad obtenida mediante contratos es justa con ciertos requisitos. Así las cosas, posible obtener una propiedad a partir del trabajo realizado en un contrato laboral. Lo que quedaba por determinar entonces era cuáles eran las condiciones en las que los contratos de trabajo eran justos desde el pensamiento del filósofo alemán. En la respuesta a este interrogante se encontró que hay al menos tres elementos que todo contrato laboral justo debe tener:

No deben existir mentiras. A excepción de las cuatro que son justas para Schopenhauer: $a$ ) la mentira como una especie de legítima defensa; b) la mentira como protectora de la propiedad privada y la intimidad personal; c) la mentira como deber cuando busca un beneficio en el otro y $d$ ) la mentira noble. Esto supone que todo contrato en el que alguno de los individuos engañe al otro es necesariamente injusto.

No debe haber padecimiento de injusticia y, por ende, tampoco remordimiento de conciencia entre los individuos que participan en el contrato.

La compasión debe estar presente como fundamento de la moral, ya que es el sustento real que hará que ninguno de individuos intente negar la voluntad del otro.

Sin embargo, al menos del primero de estos tres elementos surge una pregunta que es fundamental responder: $¿$ es posible, en la relación entre empleador-empleado, que no existan engaños? Tal y como se ha mencionado anteriormente, este tipo preguntas no encuentran una respuesta literal en esta obra de Schopenhauer. Sin embargo, hay un gran elemento que permite proponer una respuesta y es precisamente el tercero de los elementos mencionados, la compasión. 
Es esta, como fundamento de la moral, la que incentiva en últimas el obrar justo, más allá de las utilidades o beneficios que puedan traer al individuo y apoyándose en el reconocimiento del otro como ser sintiente y pasional. Otra pregunta muy diferente es si esto realmente es así en todos, o al menos la mayoría, de los contratos laborales, lo que este documento no se atreve a responder por no tener, en este caso, elementos suficientes desde la obra estudiada y porque la respuesta es más casuística que general. Este asunto deberá ser estudiado en una ocasión futura, incluso más allá del margen de la acción filosófica.

Por último, otro punto que vale la pena destacar y que surge de todo el panorama de la investigación es que se puede evidenciar aquí una posible contradicción en el pensamiento de Schopenhauer. En un primer momento, defiende fervientemente que el fundamento de toda propiedad privada debe ser exclusivamente el trabajo propio. Luego, y sobre todo en otras obras diferentes al Mundo como Voluntad y Representación, reconoce que esto está lejos de ser la realidad y que, de hecho, la gran mayoría de las propiedades, ya en su tiempo, se fundamentaban en la transferencia contractual o en la herencia. Vale la pena recordar que incluso él mismo vivió durante toda su vida de las rentas que le generaba la gran herencia que le dejó su padre $^{65}$, lo cual le permitió al menos en gran parte de su vida no tener que trabajar para poder subsistir.

\section{REFERENCIAS}

ArAmayo, Roberto, "Culpa y responsabilidad como vertientes de la conciencia moral", Isegoría, Madrid, núm. 29, 2003, disponible en: http://isegoria.revistas.csic.es/index.php/isegoria/article/view/487.

Battaglia, Felice, Filosofía del trabajo, trad. de Francisco Elías de Tejada, Madrid, Editorial Revista de Derecho Privado, 1955.

65 Al respecto, consúltese la biografía de Schopenhauer realizada por Moreno, Luis, Schopenhauer. Una biografía, cit. 
Botero, Andrés, "La teoría unificadora dialéctica de Roxin a la luz de Beccaria", Revista de Derecho Penal, Madrid, núm. 25, 2001, disponible en: http://www.rtfd.es/numero5/16-5.pdf.

Botero, Andrés, "El positivismo jurídico en la historia: las escuelas del positivismo jurídico en el Siglo XIX y primera mitad del Siglo XX", en FABRA, Jorge (ed.), Enciclopedia de filosofía y teoría del derecho, México, UNAM, 2015.

Botero, Andrés, "Schopenhauer: entre el ostracismo y los memes", Revista Filosofía UIS, Bucaramanga, vol. 17, núm. 2, 2018, disponible en: http://dx.doi.org/10.18273/revfil.v17n2-2018 001.

BOTERO, Andrés, Jurar y juzgar. Estudio sobre el juramento procesal y su evolución en Colombia, siglo XIX, Bucaramanga, Universidad Industrial de Santander, 2019.

Botero, Andrés y AguirRe, Javier, "El juramento y los dos foros: los aportes histórico-filosóficos de Paolo Prodi en relación con el rol de la religión en las democracias occidentales", Tópicos, Revista de Filosofía, México, núm. 57, 2019, disponible en: http://topicosojs.up.edu.mx/ojs/index.php/topicos/article/ view/1069.

CABos, Jordi, "Sufrimiento e individualidad en Schopenhauer", Anuario Filosófico, Navarra, vol. 47, núm. 3, 2014, disponible en: https://proyectoscio.ucv.es/wp-content/uploads/2016/03/ 03-Estudios_Cabos.pdf.

CARrillo, Lucy, "Schopenhauer: sobre individuos y sociedad", Estudios de filosofía, Medellín, núm. 37, 2008, disponible en: https://www.redalyc.org/pdf/3798/379847512006.pdf.

Hume, David, Tratado de la naturaleza humana II, trad. de Félix Duque, Buenos Aires, Orbis, 1984.

Kant, Immanuel, Crítica de la razón pura, trad. de Mario Caimi, México, FCE-UAM-UNAM, 2009.

KosSler, Matthias, "El principium individuationis en Schopenhauer y la Escolástica”, en ONCINA, Faustino (ed.), Schopenhauer en la historia de las ideas, México, Plaza y Valdés Editores, 2011. 
LóPEz, Pilar, "Voluntad y sexualidad en Schopenhauer", Thémata, Sevilla, núm. 24, 2000, disponible en: https://idus.us.es/xmlui/ handle/11441/27501.

LóPEZ, Pilar, “El kantismo de Schopenhauer: ¿herencia o lastre?”, en Oncina, Faustino (ed.), Schopenhauer en la historia de las ideas, México, Plaza y Valdés Editores, 2011.

MAgeE, Bryan, Schopenhauer, trad. de Amaia Bárcena, Madrid, Cátedra, 1991.

MARTínez, José, Schopenhauer y la crisis del concepto moderno de razón, tesis de doctorado, Murcia, Universidad de Murcia, 1998.

MATEU, Juan, La filosofía política y su trasfondo ontológico en la obra de Arthur Schopenhauer, tesis de doctorado, Valencia, Universitat de València, 2012.

Moreno, Luis, Schopenhauer. Una biografía, Madrid, Trotta, 2014.

MuÑoz-Alonso, Germán, "Reflexiones sobre Schopenhauer y su teoría del cuerpo", Revista general de información y documentación, Madrid, vol. 2, núm. 2, 1992, disponible en: https:// revistas.ucm.es/index.php/RGID/article/view/RGID9292220 093A.

MuÑoz-REJA, Vicente, "Schopenhauer: estrategias de acreditación del mundo como voluntad", Bajo Palabra, Madrid, núm. 2, 2007, disponible en: https://revistas.uam.es/bajopalabra/ article/view/3637.

PÉREz Jara, Javier, "La importancia del cuerpo como "constitutivo formal" de todo viviente en la filosofía de Schopenhauer", Thémata, Revista de Filosofía, Sevilla, núm. 44, 2011, https://re vistascientificas.us.es/index.php/themata/article/view/505.

Rabade Romeo, Sergio, "El cuerpo en Schopenhauer", Logos. Anales del Seminario de Metafísica, Madrid, vol. 23, 1989, disponible en: https://revistas.ucm.es/index.php/ASEM/article/view /ASEM8989110135A. 
RÁBADE, Ana, "La filosofía de Schopenhauer como crítica de la Ilustración", Anales del Seminario de Metafísica, Madrid, núm. 23, 1989.

Schopenhauer, Arthur, El mundo como voluntad y representación I, trad. de Pilar López de Santa María, Madrid, Trotta, 2009.

Serrano, Enrique, "Sobre el fundamento de la moral", Signos, Anuario de Humanidades, México, año X, 1996, disponible en: $h t t p s:$ //www.academia.edu/25972967/Sobre_el_fundamento_de_ la_moral.

Vincenzo, Matteo, "Trascendental, cuerpo y voluntad en Fichte y Schopenhauer", en Oncina, Faustino (ed.), Schopenhauer en la historia de las ideas, México, Plaza y Valdés Editores, 2011.

ZAPATA, Daiman, "Arthur Schopenhauer, ¿defensor del capitalismo?" Versiones, vol. 1, núm. 5, 2014, disponible en: https://apren deenlinea.udea.edu.co/revistas/index.php/versiones/article/ view/22516. 